\title{
The Impact of Thematic Learning Integrated ICT in Tabot Bengkulu as Cultural Ceremony toward Social Interaction Knowledge in Elementary School
}

\author{
Endang Widi WINARNI ${ }^{1}$ (iD \\ Endina Putri PURWANDARI ${ }^{2}$ \\ Herman LUSA ${ }^{3}$ \\ Sri DADI ${ }^{4}$
}

${ }^{, 3,4}$ Lecturer, Elementary Education Department, Education Faculty

Email:endangwidi@unib.ac.id

Email:hermanhusa@unib.ac.id

${ }^{4}$ Email:sridadi@unib.ac.id

${ }^{2}$ Lecturer, Informatics Department, Engineering Faculty University of Bengkulu, Bengkulu, Indonesia

¿Email:endinaputri@unib.ac.id

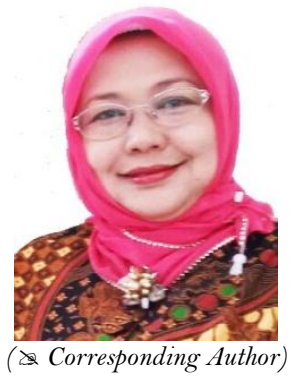

\begin{abstract}
Tabot Bengkulu as one of cultural ceremony in Bengkulu province is a cultural asset that held once a year in Muharram Month in Islamic Calendar. This ceremony has many character values in society such as religious, social care, and environment care. The use of local wisdom in learning can improve the social interaction knowledge for elementary students. The purpose of this research is to determine the impact of integrating ICT with thematic learning and discovery learning model for tabot Bengkulu as a cultural ceremony toward social interaction knowledge in elementary school. The research implemented pretest-posttest control group design. The research populations are two classes of fourth-grade students from the elementary school in Bengkulu in the academic year 2017-2018. These classes are divided into two, one class from as the experiment group with discovery learning and ICT from state elementary school 1 and the other one class as the control group with conventional media from state elementary school 22 . The instrument used to measure student knowledge about the uniqueness of my residence area. The results showed that the average score difference between posttest and pretest in the control group was 23.46 and in the experimental group of 38.12 The analysis results for $t$ value 0.13 and $\mathrm{t}$ table 2.00. It can be concluded that there is no significant effect of thematic learning based on the potential of the region with the discoveries of learning and ICT media on the knowledge of elementary students about the cultural ceremony "Tabot Bengkulu".
\end{abstract}

Keywords: Thematic learning, Regional potential, Knowledge, Cultural ceremony.

Citation | Endang Widi WINARNI; Endina Putri PURWANDARI; Herman LUSA; Sri DADI (2018). The Impact of Thematic Learning Integrated ICT in Tabot Bengkulu as Cultural Ceremony toward Social Interaction Knowledge in Elementary School. Asian Journal of Education and Training, 4(2): 70-74.

History:

Received: 26 September 2017

Revised: 16 February 2018

Accepted: 20 February 2018

Published: 23 February 2018

Licensed: This work is licensed under a Creative Commons

Attribution 3.0 License (c)

Publisher:Asian Online Journal Publishing Group
Contribution/Acknowledgement: All authors contributed to the conception and design of the study

Funding: We would like to thank the Directorate of Higher Education, Ministry of Research, Technology, and Higher Education, Republic Indonesia for financial support throughout research grant in scheme "Hibah Bersaing" $2016-2017$.

Competing Interests: The authors declare that they have no conflict of interests.

Transparency: The authors confirm that the manuscript is an honest, accurate, and transparent account of the study was reported; that no vital features of the study have been omitted; and that any discrepancies from the study as planned have been explained.

Ethical: This study follows all ethical practices during writing.

\section{Contents}

1. Introduction

2. Method

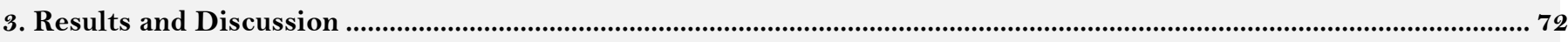

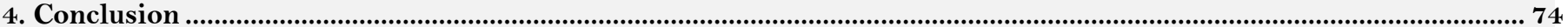

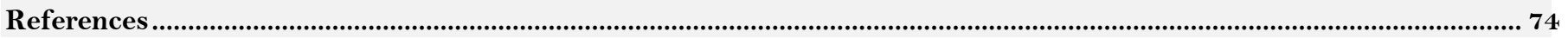




\section{Introduction}

The function of national education essentially develops the capabilities and improves the quality of life, human dignity and society in order to realize the goals of national education hence the role of teachers must undergo change. Educational programs in schools need to pay more attention to the student development in cognitive, affective, conative, and psychomotor so that the education provided to students becomes the noble character. The ideal learning is to bring students closer to their environment or to use the ethno sciences approach. Based on these descriptions, this paper presents technocracy-based learning and the development of future generations of character.

Strong characters will form a strong mental. Thomas Lickona, states that character is a person's natural traits in responding to the situation morally. In other words, that character is an attribute or trait that shapes and distinguishes the personal traits, ethical characteristics, and mental complexity of a person, a group, or a nation. Ramly (2010) states that the values of character developed in school, including religious, honest, tolerance, discipline, hard work, creative, independent, democratic, curiosity, the spirit of nationality, appreciate achievement, friendly and communicative, love peace, love reading, social care, and environment care.

Learning is essentially an interaction between individuals and environment. The environment provides stimulus to individual and vice versa. The interaction process can changes individual, in the form of behavior change. The integrated thematic learning based on local culture by using discovery learning with ICT media is expected to increase the values of character for elementary school students. ICT focused transformation is regarded positively in terms making information access easier, increasing visual learning, increasing educational quality, and more efficient (Coklar, 2013). The culture of acculturation is a combination of two or more cultures that influence by other cultures, which occur when the proponents of both cultures relate long. The second possibility of the process of interaction or communication will result in an intercultural interaction which is then shared as a collective culture. While the culture of assimilation is a blend of two or more culture, then become a new culture without any element of coercion. This process is common when two or more groups are willing to interact, open up, and feel comfortable with each other.

Characteristics of elementary students tend to study concretely, interactively, and hierarchically, therefore it is more appropriate to use integrative thematic learning. Thematic lessons emphasize theme as the unifying of various subjects that are preferred to the meaning of learning and the relevance of various concepts. Thematic learning provides direct experience to students. The focus of learning is directed to discussion with closest themes related to student life. One of the potential areas closest to students in the city of Bengkulu is Tabot as a cultural ceremony which is held every year in Muharram month from 1 to 10 Muharram. The procession of Tabot celebration, many values of cultivated character are: religious, social, and environment care.

Approaches that use local wisdom to make learning more easily understood was developed researchers. Nita et al. (2017) purpose the Indonesia educational concept with "Niteni", "Nirokake", and "Nambani" (3N) to improve the values of character for elementary school students. Approaches that use local wisdom will be more easily understood by educators. Yieng and Khadijah (2017) develop technology leadership in Malaysia's HighPerformance School (HPS). The hard work and effort by the headmaster of HPS in the field of ICT have shown a good result and outcome. Okumura (2017) said that in the recent educational environment around Japanese teacher, the use of ICT is currently promoted in education. Homeroom teachers need to equip ICT knowledge and skills in association with teaching various subjects.

Objects and events around students become meaningfully used for independent learning if written and designed in a systematic order according to instructional principles into learning resources. Principles of writing include: according to hierarchical learning, structured motivating, gradual and repetitive, and students learning outcomes.

Learning resources are everything that can be a source of learning materials and activities: (1) People (teachers, experts, practitioners, students, etc.), (2) Books and publications (references of research reports, package books), (3) Things that can be brought into class or not, (4) Images and audio-visual media, and (5) Environment (natural, social).

Based on the above description, the research purpose is: "Knowing the effect of thematic learning using discovery learning with ICT about "Tabot Ceremony" to the knowledge of elementary students about social interaction in tabot ceremony.

\section{Method}

The research implemented pretest-posttest control group design (Winarni, 2011) in Figure-1.

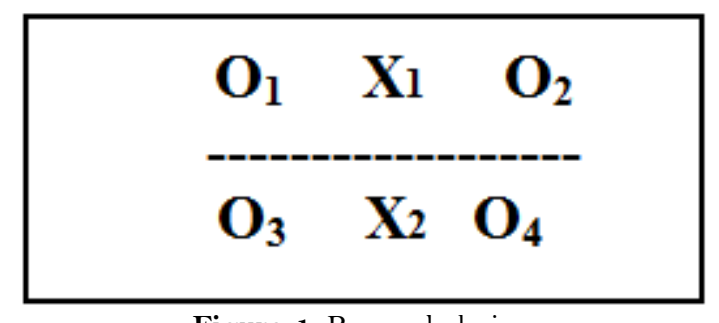

Source: Tuckman (1999)

Where:

$\mathrm{X}_{1}=$ thematic learning with Discovery Learning and ICT media

$\mathrm{X}_{2}=$ thematic learning with Discovery Learning and Tabot conventional media

$\mathrm{O}_{1}=$ pretest for the experimental class

$\mathrm{O}_{2}=$ posttest for the control class

$\mathrm{O}_{3}=$ pretest for the experimental class 
$\mathrm{O}_{4}=$ posttest for control class

The study population is all fourth-grade elementary school students in Bengkulu city of the academic year 2017-2018. The research sample is class state elementary school 1 and state elementary school 22 in the same condition determined from the different test from pretest average in control and experiment group, that is obtained t value equal to -0,25 and t table equal to 2,00. Or it can be concluded that there is no difference for the initial state in both groups. In determining the experimental and control classes conducted by cluster random sampling. According to Winarni (2011) cluster random sampling technique is used if there is a heterogeneous population in which the subpopulation is a group having heterogeneous properties, whereas in stratification samples each sub-population is homogeneous.

The instrument used in this study is a test sheet to measure students' knowledge of social interaction in the uniqueness in my residence area. The test sheets used in this research are essay-type written tests. The data obtained were analyzed using the difference of two averages with t-test. Before analyzing using t-test, two sample data have fulfilled two requirements that are normal and homogeneous distribution.

The normality test result for pretest in experiment group is $\chi^{2}$ value $=22,1$ and $\chi^{2}$ table $=43,77$. Because $\chi^{2}$ value $<\chi^{2}$ table then the experiment class distribution is normal. The normality test result for pretest in control group is $\chi^{2}$ value $=7,17$ and $\chi^{2}$ table $=38,88$. Because $\chi^{2}$ value $<\chi^{2}$ table then the control class distribution is normal. The normality test result for posttest in experiment group is $\chi^{2}$ value $=39,85$ and $\chi^{2}$ table $=43,77$. Because $\chi^{2}$ value $<\chi^{2}$ table then the experiment class distribution is normal. The normality test result for posttest in control group is $\chi^{2}$ value $=19,57$ and $\chi^{2}$ table $=38,88$. Because $\chi^{2}$ value $<\chi^{2}$ table then the control class distribution is normal. Homogeneity test results of two samples on pretest is $\mathrm{F}$ arithmetic $=1.03$ and $\mathrm{F}$ table $=1.91$. Because the price of $\mathrm{F}$ is less than the price of $\mathrm{F}$ table, the distribution of pretest data in both groups is homogeneous. The result of homogeneity test of two samples on posttest is $\mathrm{F}$ arithmetic $=1,2$ and $\mathrm{F}$ table $=1,91$. Because the price of $\mathrm{F}$ is less than the price of $\mathrm{F}$ table, the distribution of posttest data in both groups is homogeneous.

\section{Results and Discussion}

The thematic lessons developed are for basic competencies especially on social science content "understanding humans in the interaction dynamics with natural, social, cultural, and economic". The indicator is to express community interaction to the sacred Tabot ceremony in Bengkulu.

Description for students' activities on the experimental and control class lessons are as follows:

(1) Stimulation, at this stage, students are faced with something that raises a question mark, then proceeded to not give generalization, in order to arise the desire to investigate itself. In the experimental and control class, students and teachers asked questions about the contents of "Tabot Bengkulu" song.

(2) The problem statement, students are given the opportunity to identify the problem that relevant to the subject matter, then one of them is selected and formulated in a hypothesis. In the experimental and control classes grouped the problem after reading the "Tabot Bengkulu" teaching materials.

(3) Data collection, students are given the opportunity to gather as much information as possible by reading Tabot Bengkulu teaching materials and observing objects to prove whether the hypothesis is true or not. In the experimental class, students in groups with teacher guidance observed video shows of Tabot Bengkulu ceremony. While the control class observed images of Tabot Bengkulu ceremony.

(4) Data processing, at this stage all the information reading results of teaching materials and observations of video Tabot Bengkulu ceremony, are classified and interpreted as the formation of concepts and generalizations. From the generalization, students will gain new knowledge about alternative solutions that need to get a logical proof. In the experimental and control class, students discussed the social interaction that took place in Tabot Bengkulu ceremony.

(5) Verification, students do a careful examination to prove whether the hypothesis is established with alternative findings, connected with the data processing results. In the experimental class, students match the suitability between the problem in student discussion sheets with the answers from video observation and discussion. While in the control class, students match the suitability between the problem in student discussion sheets with the answers from picture observation and discussion.

(6) Generalization (conclusions), the process of drawing conclusion can serve as a general principle and applies to all occurrences or similar problems, taking into account the verification results. In the experimental and control class, students with teacher guidance concluded to result from teaching materials and video observation about Tabot Bengkulu ceremony.

Although there are similarities and differences in learning activities between experiment and control classes, it turns out posttest understanding of social interaction in Tabot Bengkulu ceremony did not show a significant difference. Recapitulation of pre-test results and student test posts is presented in Table-1.

Table-1. Pretest and posttest result student knowledge of social interaction

\begin{tabular}{l|l|l|l|l|l}
\hline \multicolumn{2}{c}{ Table-1. Pretest and posttest result student knowledge of social interaction } \\
\hline \multirow{2}{*}{ Num } & \multirow{2}{*}{ Result } & Experiment Class & \multicolumn{2}{l}{ Control Class } \\
\cline { 3 - 6 } & & Pretest & Posttest & Pretest & Posttest \\
\hline 1. & Highest & 100 & 100 & 100 & 100 \\
\hline 2 & Lowest & 30 & 45 & 35 & 50 \\
\hline 3 & Average & 28.13 & 66.25 & 37.69 & 61.45 \\
\hline 4 & Standard deviation & 37.97 & 37.65 & 37.45 & 41.21 \\
\hline
\end{tabular}

The results showed that the thematic learning using Discovery Learning model with ICT media can increase the knowledge of elementary students about social interaction that occurs in Tabot Bengkulu ceremony about $57.54 \%$. While the thematic learning using the Discovery Learning model with teaching materials and 
conventional image media can increase the knowledge of elementary students about social interaction in Tabot Bengkulu ceremony about $38.36 \%$.

Based on the results of inferential statistical analysis shows that t-score 0.13 is smaller than $5 \%$ significant level of 2.00 , then $\mathrm{H}_{0}$ is accepted, so it can be concluded that there is no significant effect of thematic learning using discovery learning model with ICT media to social interaction knowledge in Tabot Bengkulu ceremony.

Discovery Learning is an attempt to understand concepts, meanings, and relationships, through an intuitive process to finally come to a conclusion (Winarni, 2012). Discovery using local cultural sources like Tabot is an annual event that occurs in the environment around students so that makes observation, classification, prediction, and determination more contextual. Discovery learning resources are not presented in final concept information, students are required to perform various activities to collect information, compare, categorize, analyze, integrate, reorganize materials, and make conclusions.

In this learning model, teacher role as a facilitator while student find and experience own. Winarni (2012) statement that the attitude is formed by students interaction, by applying the student's interaction actively looking for information that can be applied problems solving in daily life. Students actively ask questions, conduct group discussions, work together to solve problems, mutual provide ideas in the learning process, respect friend's opinions, and dare to defend opinions by showing evidence. From such activities, the desired attitude of the students will arise.

The analysis result is in accordance with Wibowo (2012) that character values as one of graduate's competency aspect are holistic and their achievement is done through the process of receiving, running, appreciating, living, and practicing. Integrated thematic learning based on local culture with ICT media or conventional images can develop character values because learning is learner's interaction process with educators and learning resources in the learning environment.

The use of media in accordance with Winarni (2016) that learning is a channel or intermediary learning messages stimulate thoughts, feelings, and willingness conveyed by teachers to students with the aim that the message can be absorbed quickly by students accordingly with purpose. Learning media can work for teachers and students. For teachers, the learning media serves as a tool for teachers to simplify, simplify and accelerate the process of teaching and learning, presenting information, designing the scope of information and skills systematically according to the level of ability and time allocation. While the learning media for students serves as a tool in activating psychological function in him. Thus it can be concluded that the learning media can build conditions that make students able to gain attitudes, knowledge, and skills.

The results showed that the concept of social interaction occurring in "Tabot Bengkulu Ceremony" did not show any significant difference between the students in the experimental class using ICT media with students in the control group using conventional media. Baugh (in Arsyad (2009)) discloses the findings of this study relevant to previous studies of experts, that approximately $90 \%$ of a person's learning outcomes are obtained through the senses of view, and only about $5 \%$ is acquired through the senses of hearing, and $5 \%$ more with other senses. The social interaction concept that occurs in "Tabot Bengkulu Ceremony" for elementary school students in Bengkulu city is very familiar because almost $100 \%$ of students have observed directly during Tabot celebration held once every year. These direct observations make the learning experience level build a communication process. It showed that Tabot experience can help children to absorb information.

The environment provides a stimulus to the individual and otherwise, the individual responds to the environment. The interaction processes can change in the individual behavior changes both positively and negatively. Johnson (2002) states that learning should bridge the blend of student culture with scientific culture in schools so as to streamline student learning. Students will learn formally to understand their environment with various problems around them. Thus, there will be didactical phenomenology which implies that in learning the concepts, principles, and other materials in science, students need to depart from problems in the contextual world. Students in the environment and observe objects and subjects contextually during the learning process can improve students' thinking development. Subsequent impacts will make students have environmental awareness.

Real-life-oriented learning has proven to be very helpful and valuable in the context of students' daily life (Borko and Putnam, 1998). Meanwhile, the new concept that students learn in the classroom will be more easily accepted by students if it is related to the knowledge scheme they have, so there is assimilation or association process. If the new conception adds or enriches the thinking schemes that students have previously possessed, this can be said to have assimilated; while the association process occurs if the new conception turns or modifies a previously existing scheme.

Learning only occurs when students process information or new knowledge in such a way that it is felt to be reasonable in terms of the frame of mind it has (memory, experience, and response). This approach assumes that the mind naturally seeks the meaning of context according to the real situation of one's environment, and that can occur through the search for a reasonable and useful relationship. Contextual learning presents a concept that links the subject matter learned by the student to the context in which the material is used, and relates to how one learns or the way students learn. Through the context of their lives, and find meaning in the learning process, so that learning will become more meaningful and fun.

A meaningful, thematic lesson that facilitates students actively solves the problems that he gets according to the concept of the material being studied. One concept that is familiar with the environment is the concept of human activity that can affect the balance of nature. This concept becomes more meaningful if in the lessons students are invited directly to the field to investigate the problems they face "(Badeni et al., 2014). Through this learning, students' learning outcomes will be maximized if students are taught in contextual nuances in which the student does not passively receive knowledge and skills but he or she has experienced actively involved by using as many elements of his senses (listening, seeing, feeling, feeling and doing) about what is learned or the social environment both individually and in groups.

The social environment as a source of learning concerns human interaction with social life, such as social organization, customs, livelihood, culture, education, population, government structure, religion and value system. The social environment is very appropriate to study the social sciences and humanity 


\section{Conclusion}

Implementation of thematic learning using Discovery Learning model with teaching materials and ICT media can increase the knowledge of elementary students about social interaction that occurs in Tabot Bengkulu ceremony of $57.54 \%$. While the implementation of thematic learning using the Discovery Learning model with teaching materials and image media can increase the knowledge of elementary students about social interaction that occurs in Tabot Bengkulu ceremony for $38.36 \%$. There is no significant effect of thematic learning using Discovery learning model with ICT media to elementary school student's knowledge about social interaction that happened in Tabot Bengkulu ceremony.

Teachers in learning should use learning resources and contextual media that are available to students because it creates observation, classification, prediction, and determination. With learning resources and contextual media, students are able to perform various activities of collecting information, comparing, categorizing, analyzing, integrating, reorganizing materials and making meaningful conclusions in solving their lives.

\section{References}

Arsyad, A., 2009. Instructional media. Jakarta: Rajawali Pers.

Badeni, S. Sri and M. Agus, 2014. Character education model based local wisdom for elementary school students. Journal of Elementary School, 1(1): 19-20.

Borko, H. and R. Putnam, 1998. The role of context in teacher learning and teacher education. In contextual teaching and learning: Preparing teachers to enhance student success in and beyond school. Columbus, Ohio, USA: ERIC. pp: 35-74.

Coklar, A.N., 2013. Areas affected most by students from the ICT focused technological transformations and its effects on education. Mediterranean Journal of Social Sciences, 4(9): 249-252. View at Google Scholar | View at Publisher

Johnson, E.B., 2002. Contextual teaching learning. California: Corwin Press.

Nita, C.I.R., J. Muhammad, S. Totok and S. Suminto, 2017. Niteni, Niroake, Nambani (3N) concept in the learning of dance in elementary school. Mediteranean Journal of Social Sciences, 8(5 S1): 137-142. View at Google Scholar

Okumura, S., 2017. Homeroom teachers or specialist teachers? Considerations for the workforce for teaching english as a subject at elementary schools in Japan. Asian Journal of Education and Training, 3(1): 1-5. View at Google Scholar $\mid$ View at Publisher

Ramly, M., 2010. Development of cultural education and nation character. Jakarta: Ministry of National Education.

Tuckman, B.W., 1999. Conducting educational research. Orlando, United States of America: Harcourt Brace College Publishers.

Wibowo, A., 2012. Character building character building character building nations facing. Jogyakarta: Pustaka Belajar.

Winarni, E.W., 2011. Educational research. Bengkulu: FKIP Unib Press.

Winarni, E.W., 2012. Innovation in science lesson. Bengkulu: FKIP UNIB.

Winarni, E.W., 2016. Environmental-based character education to build competence for future generation. Presented in International Conference. University Malaysia Sabah. September 22nd.

Yieng, W.A. and B.D. Khadijah, 2017. Technology leadership in Malaysia's high performance school. Journal of Education and e-Learning Research, 4(1): 8-14. View at Google Scholar | View at Publisher 